\title{
a-Ferrous oxalate dihydrate: a simple coordination polymer featuring photocatalytic and photo-initiated Fenton oxidations
}

\author{
Xiangqian Fan, Lingxia Zhang*, Mengli Li, Min Wang, Xiaoxia Zhou, Ruolin Cheng, \\ Yajun Zhou and Jianlin Shi*
}

\begin{abstract}
As a kind of efficient photocatalyst, coordination polymers (CPs) have gained much attention in recent years. However, their safety issue and time-consuming synthesis impede their practical application. Here in this paper we first demonstrate the facile synthesis and photocatalytic degradation performance of 1D $\alpha$-ferrous oxalate dihydrate ( $\alpha-F O D)$, which is one of the simplest CPs. A unique two-pathway photocatalytic mechanism which combines traditional photocatalytic and photo-initiated Fenton oxidations has been proposed. The excellent photocatalytic performance and cost-effective fabrication make $\alpha$-FOD a new promising candidate for the photocatalytic degradation of organic pollutants in practical applications.
\end{abstract}

Keywords: $\alpha$-ferrous oxalate dihydrate, coordination polymer, photocatalysis, Fenton reaction, RhB degradation

\section{INTRODUCTION}

Semiconductor-based photocatalysis has attracted worldwide attention since the discovery of photo-induced water splitting on $\mathrm{TiO}_{2}$ electrodes [1]. One of its important applications is to purify water and air by thoroughly mineralizing organic compounds into less toxic/nontoxic small molecules [2-5]. Numbers of classic semiconductors such as $\mathrm{TiO}_{2}$ [6-8], $\mathrm{ZnO}$ [9-11], $\mathrm{WO}_{3}$ [12-14], $\mathrm{Cu}_{2} \mathrm{O}$ [15], $\mathrm{Ta}_{2} \mathrm{O}_{5}$ [16] and g- $\mathrm{C}_{3} \mathrm{~N}_{4}[17,18]$ have been broadly studied and applied in the degradation of organic pollutants. However, these photocatalysts often suffer from drawbacks such as non/poor visible-light response, high-cost, low photo-stability, etc. Thus researchers have been looking for novel photocatalysts, which are expected to have better availability in practical applications.

As an emerging family of crystalline inorganic-organic hybrid materials, coordination polymers (CPs), in which metal ions/clusters are linked by organic ligands to form extended networks, have been demonstrated to be a new kind of very promising photocatalyst in recent years [19-27]. The greatest advantage of CPs as photocatalysts is their diverse skeletons and electronic structures which can be tailored by selecting various types of metal ions and bridging ligands, making them possible for initiating a variety of specific photocatalytic reactions [28]. In addition, a great number of them are visible-light responsive and have good photo-stability. However, the commonly used solvothermal method which involves the use of autoclaves and slow diffusion process in fabricating existing $\mathrm{CP}$ photocatalysts is unsafe and time-consuming, making the practical application of these photocatalysts difficult [23]. In addition, the structure of these well-established CP photocatalysts is always complicated, which will make the exploration of the nature of their photocatalytic performance difficult. Thus it is of great significance to develop a CP photocatalyst with simple structure by a cost-effective fabrication process.

\section{EXPERIMENTAL SECTION}

\section{Material preparation}

$\mathrm{FeSO}_{4} \cdot 7 \mathrm{H}_{2} \mathrm{O}(>99 \%)$ and $\left(\mathrm{NH}_{4}\right)_{2} \mathrm{C}_{2} \mathrm{O}_{4} \cdot \mathrm{H}_{2} \mathrm{O}(>99.5 \%)$ were purchased from Sinopharm Chemical Reagent Co. Ltd. and used without further purification. In a typical synthesis procedure, $\mathrm{FeSO}_{4} \cdot 7 \mathrm{H}_{2} \mathrm{O}(0.01 \mathrm{~mol})$ was dissolved in $70 \mathrm{~mL}$ deionized water and $0.015 \mathrm{~mol}$ of $\left(\mathrm{NH}_{4}\right)_{2} \mathrm{C}_{2} \mathrm{O}_{4} \cdot \mathrm{H}_{2} \mathrm{O}$ was dissolved in $20 \mathrm{~mL}$ deionized water at $60^{\circ} \mathrm{C}$, respectively. Then the latter solution was added dropwise into the former solution under magnetic stirring, during which a yellow precipitate formed. The suspension was stirred

State Key Laboratory of High Performance Ceramics and Superfine Microstructure, Shanghai Institute of Ceramics, Chinese Academy of Sciences, Shanghai 200050, China

*Corresponding authors (emails: zhlingxia@mail.sic.ac.cn (Zhang L); jlshi@mail.sic.ac.cn (Shi J)) 
for another $2 \mathrm{~h}$ at $80^{\circ} \mathrm{C}$. The resultant precipitate was then centrifuged, washed with deionized water and ethanol, and dried at $60^{\circ} \mathrm{C}$ in air overnight.

\section{Characterization}

X-ray diffraction (XRD) patterns were recorded on a Rigaku Ultima IV diffractometer. Fourier transform infrared (FT-IR) spectra were obtained with Nicolet iS10 FTIR spectrometer. Transmission electron microscopy (TEM) images were obtained with a transmission electron microscope (JEM-1400). Scanning electron microscopy (SEM) image was obtained on a field emission scanning electron microscope (FEI Magellan 400). Brunauer-Emmett-Teller (BET) surface area was measured at a Micromeritics Tristar 3000 system. UV-vis diffuse reflectance spectra were performed on a Shimadzu UV-3600 spectrophotometer. Photoluminescence (PL) spectrum was performed on a Shimadzu RF-5301 spectrometer. The concentration of iron ions was analyzed by an inductively coupled plasma optical emission spectroscope (ICP-OES) instrument (Agilent 725). $\mathrm{pH}$ was detected by a Leici PHSJ-4F pH meter.

\section{Theoretical calculations}

The electronic structure calculations were performed by using the density-functional theory (DFT) as implemented in the plance-wave-basis-set VASP code [29]. The energy cutoff for the plane-wave expansion was set to $520 \mathrm{eV}$. Projector augmented wave potentials were used to describe the electron-ion interaction [30]. The Ceperley and Alder form of local density approximation [31] is used for exchange and correlation. A Hubbard model U correction [32] is incorporated for the d electrons to give a better description of this strongly correlated system. The $U$ parameters used for Fe is $4.08 \mathrm{eV}$. The Brillouin-zone was sampled according to the Monkhorst-Pack scheme using a $\Gamma$ centered $k$-point mesh of $5 \times 10 \times 6$ for a conventional unit cell of $\alpha$-FOD.

\section{Electrochemical analysis}

The working electrode was obtained by an electrophoretic deposition method [33]. In detail, $40 \mathrm{mg}$ of $\alpha$-FOD was suspended in $30 \mathrm{~mL}$ acetone solution containing $20 \mathrm{mg}$ iodine under ultrasonic treatment. The deposition was conducted with a two-electrode process at the applied bias of $10 \mathrm{~V}$ for $5 \mathrm{~min}$, where both electrodes were fluorine doped tin oxide substrates (the surface area coated in the solution is $1.5 \mathrm{~cm}$ $\times 2 \mathrm{~cm}$ ). The resultant electrode was then dried at $100^{\circ} \mathrm{C}$ for $4 \mathrm{~h}$. Electrochemical measurements were conducted with a CHI 760 electrochemical workstation in a conventional three electrode cell, using a Pt plate and an Ag/AgCl electrode as counter electrode and reference electrode, respectively. An aqueous solution of $0.2 \mathrm{~mol} \mathrm{~L}^{-1} \mathrm{Na}_{2} \mathrm{SO}_{4}$ was chosen as the supporting electrolyte and was purged with $\mathrm{N}_{2}$ to remove $\mathrm{O}_{2}$ before any measurements. The photocurrent experiments were carried out under $0.4 \mathrm{~V}$ ss. $\mathrm{Ag} / \mathrm{AgCl}$.

\section{$\mathrm{OH}^{\bullet}$ measurements}

$40 \mathrm{mg}$ of the photocatalyst was suspended in $100 \mathrm{~mL} 0.1$ mol L ${ }^{-1}$ acetate buffer ( $\mathrm{pH}$ 5.5) containing $20 \mathrm{mg}$ terephthalic acid. Before exposure to light, the suspensions were stirred in the dark for $30 \mathrm{~min}$. A $300 \mathrm{~W}$ Xe lamp equipped with a specific optical cut-off filter $(\lambda>280 \mathrm{~nm}$ for UV-vis light and $\lambda>420 \mathrm{~nm}$ for visible light) was chosen as the light source. About $3.5 \mathrm{~mL}$ of the solution was removed after 10 -min reaction and filtered for fluorescence spectroscopy measurements. The excitation light wavelength used in recording fluorescence spectra was $320 \mathrm{~nm}$.

\section{Photocatalytic degradation experiment}

Rhodamine $\mathrm{B}(\mathrm{RhB})$ photodegradation was conducted by adding $100 \mathrm{mg}$ photocatalyst into $100 \mathrm{~mL}$ of $10 \mathrm{mg} \mathrm{L}^{-1} \mathrm{RhB}$ aqueous solution. A $300 \mathrm{~W}$ Xe lamp equipped with a specific optical cut-off filter $(\lambda>280 \mathrm{~nm}$ for $U V$-vis light and $\lambda>420 \mathrm{~nm}$ for visible light) was chosen as the light source. The suspensions were stirred in the dark for $1 \mathrm{~h}$ to establish an adsorption-desorption equilibrium before irradiation. During the photodegradation, about $3.5 \mathrm{~mL}$ of the suspension was collected at a regular interval. After filtration, the absorbance of the solution was detected by a Shimadzu UV-3600 spectrophotometer.

\section{RESULTS AND DISCUSSION}

Ferrous oxalate dihydrate $\left(\mathrm{Fe}\left(\mathrm{C}_{2} \mathrm{O}_{4}\right) \cdot 2 \mathrm{H}_{2} \mathrm{O}\right.$, hereafter abbreviated as FOD), so-called humboldtine in mineralogy, is one of the simplest CPs [34]. It has two polymorphs: $\alpha$-FOD and $\beta$-FOD. The $\alpha$-FOD which was assigned to monoclinic space group $C 2 / c$ with $Z=4$ (unit cell: $a=$ $12.011 \AA, b=5.557 \AA, c=9.920 \AA, \beta=128.53^{\circ}$ ) [35] is a more stable phase at standard temperature and pressure (STP). Its crystal structure consists of one-dimensional (1D) chains composed of $\mathrm{Fe}^{2+}$ and oxalate units, where the oxalate acts as a bridging ligand. Each $\mathrm{Fe}^{2+}$ is additionally coordinated to two water molecules, resulting in a distorted octahedral $\mathrm{MO}_{6}$ environment (Fig. 1a) [36]. It can be precipitated from a ferrous salt solution mixed with oxalic acid or ammonium oxalate, which is a very simple and cost-effective fabrication process. Figs S1a and S1b show the XRD pattern and FT-IR spectrum of the as-synthesized 
a

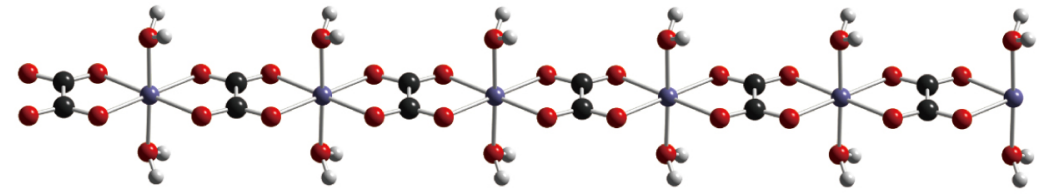

b

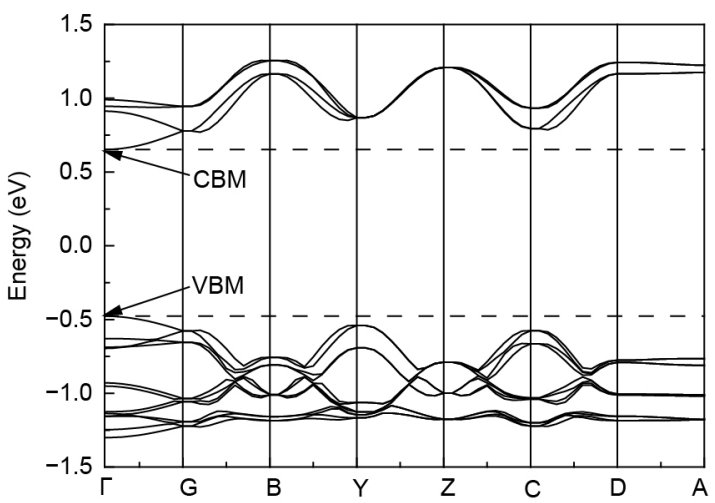

Figure 1 (a) Structure of the 1D molecular chain in a-FOD. Fe atoms are shown in grey, oxygen in red, carbon in black, and hydrogen in white; (b) calculated electronic band structures for the unit cell of $\alpha$-FOD crystals.

a-FOD, respectively, which agree well with the literature data [37]. TEM and SEM images (Fig. S2) of the $\alpha$-FOD demonstrate its irregular cuboid-shaped morphology of about $2-5 \mu \mathrm{m}$ in size. The BET surface area determined by nitrogen adsorption-desorption analysis (Fig. S3) is rather low at $1.3 \mathrm{~m}^{2} \mathrm{~g}^{-1}$. In addition, it is insoluble in water: the concentration of $\mathrm{Fe}^{2+}$ in $\alpha$-FOD suspension $(0.1 \mathrm{~g}$ a-FOD dispersed in $100 \mathrm{~mL}$ water) is only $11.5 \mathrm{mg} \mathrm{L}^{-1}$ at room temperature.

The UV-vis absorption spectrum in Fig. 2a shows typical semiconductor optical characteristics for $\alpha$-FOD. There are two absorption bands. The band at around $210 \mathrm{~nm}$ can be attributed to charge transfer absorption, while the band located at around $360 \mathrm{~nm}$ is assigned to ${ }^{5} T_{2 \mathrm{~g}} \rightarrow{ }^{5} E_{\mathrm{g}}$ absorption. The PL spectrum (Fig. 2b) gives two corresponding emission peaks centred at about 360 and $470 \mathrm{~nm}$, respectively.
The band gap of $\alpha$-FOD determined by a classical Tauc approach [38] (Fig. S4) is $2.17 \mathrm{eV}$. To analyze the electronic structure of $\alpha$-FOD, DFT calculations were carried out (Fig. 1b). The calculated band structure reveals a direct band gap of $1.13 \mathrm{eV}$ at the $\Gamma$ point, which is $1.04 \mathrm{eV}$ smaller than the experimental value. The pronounced band gap underestimation in semiconductors is a well-known defect in DFT calculations [39].

The photocurrent measurements in Fig. 3a confirmed the semiconductor characteristic of $\alpha$-FOD. The photocurrent under UV-vis light is higher than that under visible light due to its high proportion of high-energy photons. It is known that the photocatalytic oxidation and reduction abilities of semiconductors are determined by their valence and conduction band, respectively $[40,41]$. To determine the band gap structure of $a-F O D$, the electrochemical
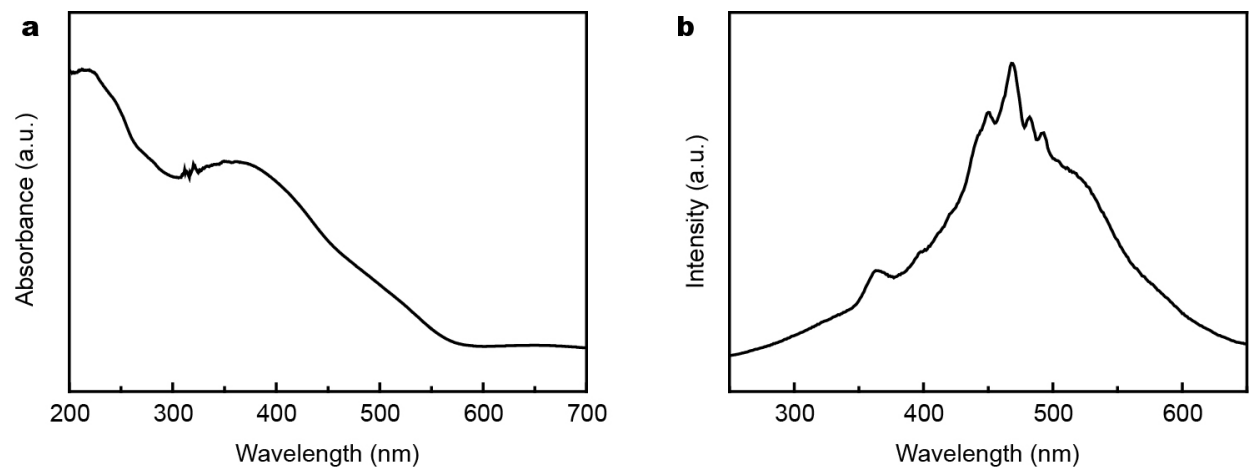

Figure 2 (a) UV-vis absorption spectrum of $\alpha$-FOD and (b) PL spectrum (excitation wavelength $=220 \mathrm{~nm}$ ) of $\alpha$-FOD suspension. 

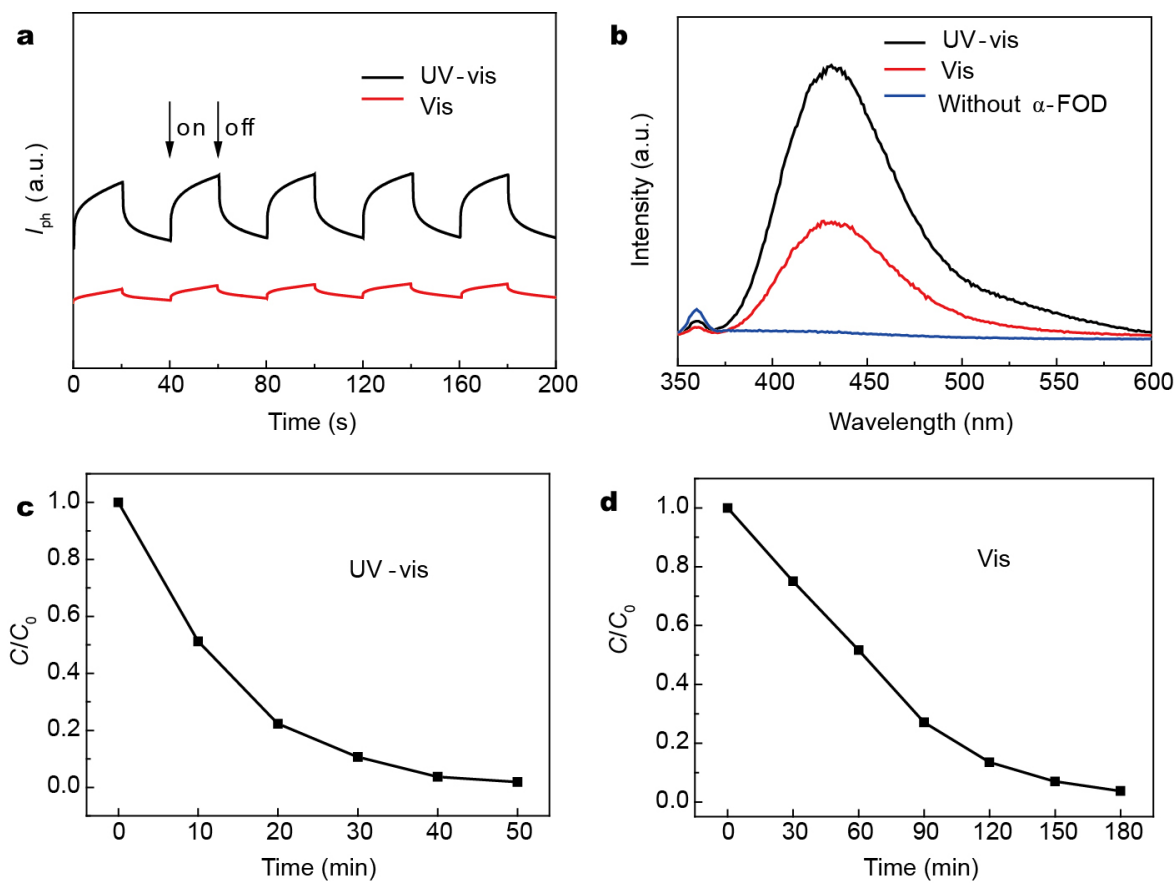

Figure 3 (a) Periodic on/off photocurrent response of $\alpha$-FOD under UV-vis $(\lambda>280 \mathrm{~nm})$ and visible light $(\lambda>420 \mathrm{~nm})$ irradiation; (b) PL spectra (excitation wavelength $=320 \mathrm{~nm}$ ) of 2-hydroxyterephthalic acid in $\alpha$-FOD suspension after 10-min UV-vis and visible light irradiation; time course of $\mathrm{RhB}$ degradation on $\alpha$-FOD under UV-vis (c) and visible light (d) irradiation.

Mott-Schottky plot was obtained. Fig. S5 reveals a typical n-type characteristic of $\alpha$-FOD. The flat-band potential (equivalent to the potential of conduction edge for an n-type semiconductor [42]) is determined to be $0.18 \mathrm{~V} v s$. normal hydrogen electrode (NHE). The valence edge potential is then calculated to be $2.35 \mathrm{~V}$ by using the formula $E_{\mathrm{g}}=E_{\mathrm{v}}-E_{\mathrm{c}}\left(E_{\mathrm{g}}\right.$ : band gap, $E_{\mathrm{v}}$ : VB potential, $E_{\mathrm{c}}$ : CB potential). According to its conduction edge potential, $\alpha$-FOD should be unable to drive a number of important photoreduction reactions like fuel evolution by water/carbon dioxide reduction. However considering the position of its valence edge potential (Fig. 4a), the oxidation potential of photo-generated holes in $\alpha$-FOD is large enough to oxidize $\mathrm{OH}^{-}$to $\mathrm{OH}^{\bullet}$, which is the most active species in degrading organic pollutants.

To further verify the existence of $\mathrm{OH}^{*}$ in $\alpha$-FOD-based photocatalytic system, here a widely used method for $\mathrm{OH}^{*}$ detection was adopted. It is known that $\mathrm{OH}^{*}$ can react with terephthalic acid (a non-fluorescent agent) to generate 2-hydroxyterephthalic acid, which can emit an intense fluorescence signal with its peak centred at ca. $426 \mathrm{~nm}$ under UV-light excitation (Fig. S6) [43]. As shown in Fig. 3b, an obvious fluorescent signal related to $\mathrm{TAOH}$ can be observed in a-FOD suspension under both UV-vis and visible light irradiation, confirming the generation of $\mathrm{OH}^{*}$ during photocatalytic process.
$\mathrm{RhB}$ is a very common probe pollutant used to evaluate the photooxidation ability of photocatalysts. Figs $3 \mathrm{c}$ and $\mathrm{d}$ show the RhB photodegradation on $\alpha$-FOD under UV-vis and visible light illumination, respectively. The RhB undergoes pronounced decomposition and can be thoroughly decomposed under both UV-vis and visible light illuminations. The photocatalytic activity of $a$-FOD does not show pronounced decrease after three cycles (Fig. S7). In addition, the XRD patterns of $\alpha$-FOD before and after photodegradation also remain unchanged (Fig. S8), demonstrating its good photostability. Generally, the photooxidation capability of a photocatalyst in anaqueous system is contributed by photo-generated holes and $\mathrm{OH}^{*}$ species. In terms of the electronic potential of $\alpha$-FOD and electrode potential of relevant redox couples (Fig. 4a), the photogenerated holes and hole-derived $\mathrm{OH}^{*}$ should make contributions to the photooxidation performance of $\alpha$-FOD. In addition, $\mathrm{H}_{2} \mathrm{O}_{2}$ can be generated by the reaction: $\mathrm{O}_{2}+$ $2 \mathrm{H}^{+}+2 \mathrm{e}^{-} \rightarrow \mathrm{H}_{2} \mathrm{O}_{2}$ (Fig. 4a) under the initiation of photo-induced electrons at the conduction band, which will enable a free radical chain reaction with the $\mathrm{Fe}^{2+}$ ions, i.e., Fenton reaction, in bulk $\alpha$-FOD or in solution, thus a considerable quantity of $\mathrm{OH}^{*}$ species can be generated from the $\mathrm{Fe}^{2+} / \mathrm{H}_{2} \mathrm{O}_{2}$ pairs in acidic environment ( $\mathrm{pH} 5.7$ in this a-FOD system). This famous Fenton reaction has been widely applied in organic pollutant degradation [44-46], 

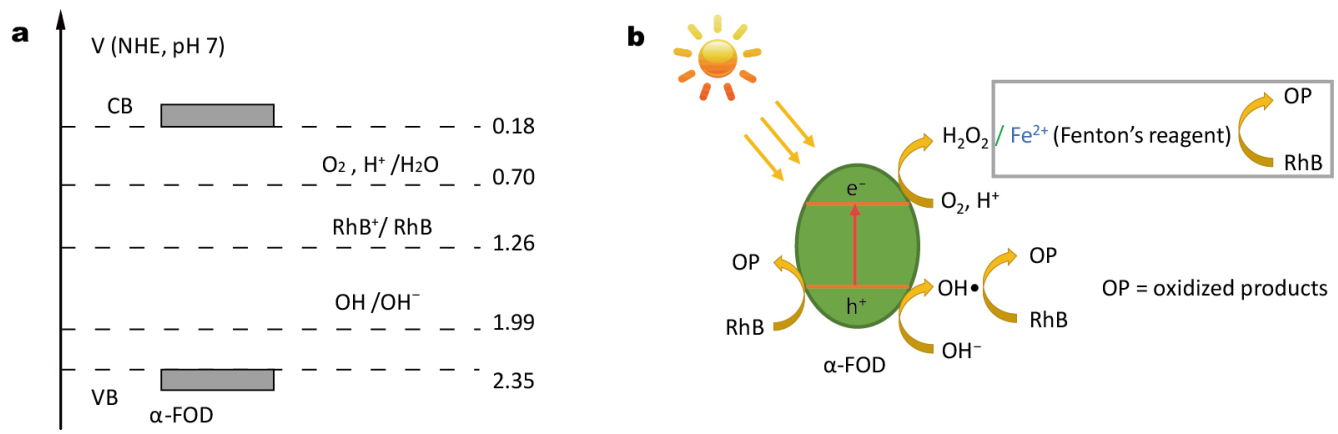

Figure 4 (a) Electronic potential diagram of $\alpha$-FOD and electrode potentials of related redox couples. (b) Proposed reaction mechanism for the photocatalytic degradation of $\mathrm{RhB}$ aqueous solution over $\alpha$-FOD-based system.

and therefore would undoubtedly enhance the photocatalytic activity in oxidizing the dye in the present $\alpha$-FODbased photocatalytic system. Based on discussions above, the catalytic mechanism is illustrated in Fig. 4b. Simply speaking, there are two catalytic paths: one is traditional photocatalytic oxidation and the other is photo-initiated Fenton oxidation. The unique composition of $\alpha$-FOD makes it one of the most unique photocatalysts combining these two catalytic oxidation paths without introducing any additional reagents such as most-frequently used hydrogen peroxide.

\section{CONCLUSION}

In summary, a-FOD was discovered to be the simplest coordination polymer photocatalyst. It shows excellent photocatalytic performance in organic pollutant degradation. The structural and electronic characteristics were investigated in detail. Based on the electronic structure and composition analysis of $\alpha$-FOD, a unique catalytic mechanism combining two paths including traditional photocatalytic oxidation and photo-initiated Fenton oxidation was proposed. The excellent photocatalytic performance and cost-effective fabrication makes it a promising candidate for photocatalytic pollutant degradation in practical applications. In future, in order to achieve enhanced photocatalytic performance or broaden its photocatalytic applications, further research can be focused on the morphology and structure control by the strategies such as nanoscaling, doping and coupling with other photocatalysts.

Received 4 May 2016; accepted 6 June 2016; published online 22 July 2016

1 Fujishima A, Honda K. Electrochemical photolysis of water at a semiconductor electrode. Nature, 1972, 238: 37-38

2 Legrini O, Oliveros E, Braun AM. Photochemical processes for water treatment. Chem Rev, 1993, 93: 671-698

3 Wang S, Ang HM, Tade MO. Volatile organic compounds in indoor environment and photocatalytic oxidation: state of the art. Environment Int, 2007, 33: 694-705

4 Qu X, Brame J, Li Q, et al. Nanotechnology for a safe and sustainable water supply: enabling integrated water treatment and reuse. Acc Chem Res, 2013, 46: 834-843

5 Yue D, Qian X, Zhao Y. Photocatalytic remediation of ionic pollutant. Sci Bull, 2015, 60: 1791-1806

6 Li D, Haneda H, Hishita S, et al. Visible-light-driven $\mathrm{N}-\mathrm{F}$-codoped $\mathrm{TiO}_{2}$ photocatalysts. 2. Optical characterization, photocatalysis, and potential application to air purification. Chem Mater, 2005, 17: 2596-2602

7 Asahi R. Visible-light photocatalysis in nitrogen-doped titanium oxides. Science, 2001, 293: 269-271

8 Xiong Z, Zhao XS. Nitrogen-doped titanate-anatase core-shell nanobelts with exposed $\{101\}$ anatase facets and enhanced visible light photocatalytic activity. J Am Chem Soc, 2012, 134: 5754-5757

9 Zhang L, Cheng H, Zong R, et al. Photocorrosion suppression of $\mathrm{ZnO}$ nanoparticles via hybridization with graphite-like carbon and enhanced photocatalytic activity. J Phys Chem C, 2009, 113: 2368-2374

10 Wang Y, Shi R, Lin J, et al. Enhancement of photocurrent and photocatalytic activity of $\mathrm{ZnO}$ hybridized with graphite-like $\mathrm{C}_{3} \mathrm{~N}_{4}$. Energy Environ Sci, 2011, 4: 2922-2329

11 He W, Kim HK, Wamer WG, et al. Photogenerated charge carriers and reactive oxygen species in $\mathrm{ZnO} / \mathrm{Au}$ hybrid nanostructures with enhanced photocatalytic and antibacterial activity. J Am Chem Soc, 2014, 136: 750-757

12 Zhao ZG, Miyauchi M. Nanoporous-walled tungsten oxide nanotubes as highly active visible-light-driven photocatalysts. Angew Chem Int Ed, 2008, 47: 7051-7055

13 Depuccio DP, Botella P, O'rourke B, et al. Degradation of methylene blue using porous $\mathrm{WO}_{3}, \mathrm{SiO}_{2}-\mathrm{WO}_{3}$, and their Au-loaded analogs: adsorption and photocatalytic studies. ACS Appl Mater Interfaces, 2015, 7: 1987-1996

14 Mei L, Zhao H, Lu B. Ultra-efficient photocatalytic properties in porous tungsten oxide/graphene film under visible light irradiation. Adv Sci, 2015, 2: 1500116

15 Liang Y, Shang L, Bian T, et al. Shape-controlled synthesis of polyhedral 50-facet $\mathrm{Cu}_{2} \mathrm{O}$ microcrystals with high-index facets. CrystEngComm, 2012, 14: 4431-4436

16 Zhou C, Shang L, Yu H, et al. Mesoporous plasmonic Au-loaded $\mathrm{Ta}_{2} \mathrm{O}_{5}$ nanocomposites for efficient visible light photocatalysis. Catal Today, 2014, 225: 158-163

17 Wang X, Chen X, Thomas A, et al. Metal-containing carbon nitride compounds: a new functional organic-metal hybrid material. Adv 
Mater, 2009, 21: 1609-1612

18 Dong F, Wang Z, Li Y, et al. Immobilization of polymeric g- $\mathrm{C}_{3} \mathrm{~N}_{4}$ on structured ceramic foam for efficient visible light photocatalytic air purification with real indoor illumination. Environ Sci Technol, 2014, 48: 10345-10353

19 Wang C, Xie Z, Dekrafft KE, et al. Doping metal-organic frameworks for water oxidation, carbon dioxide reduction, and organic photocatalysis. J Am Chem Soc, 2011, 133: 13445-13454

20 Fateeva A, Chater PA, Ireland CP, et al. A water-stable porphyrinbased metal-organic framework active for visible-light photocatalysis. Angew Chem Int Ed, 2012, 51: 7440-7444

21 Wen T, Zhang DX, Zhang J. Two-dimensional copper(I) coordination polymer materials as photocatalysts for the degradation of organic dyes. Inorg Chem, 2013, 52: 12-14

22 Zhang T, Lin W. Metal-organic frameworks for artificial photosynthesis and photocatalysis. Chem Soc Rev, 2014, 43: 5982-5993

23 Wang CC, Li JR, Lv XL, et al. Photocatalytic organic pollutants degradation in metal-organic frameworks. Energy Environ Sci, 2014, 7: 2831-2867

24 Meyer K, Ranocchiari M, Van bokhoven JA. Metal organic frameworks for photo-catalytic water splitting. Energy Environ Sci, 2015, 8: $1923-1937$

25 Dai M, Li HX, Lang JP. New approaches to the degradation of organic dyes, and nitro- and chloroaromatics using coordination polymers as photocatalysts. CrystEngComm, 2015, 17: 4741-4753

26 Wu XY, Qi HX, Ning JJ, et al. One silver(I)/tetraphosphine coordination polymer showing good catalytic performance in the photodegradation of nitroaromatics in aqueous solution. Appl Catalysis B-Environ, 2015, 168-169: 98-104

27 Shi L, Wang T, Zhang H, et al. An amine-functionalized iron(III) metal-organic framework as efficient visible-light photocatalyst for Cr(VI) reduction. Adv Sci, 2015, 2: 1500006

28 Liu L, Wu D, Zhao B, et al. Copper(II) coordination polymers: tunable structures and a different activation effect of hydrogen peroxide for the degradation of methyl orange under visible light irradiation. Dalton Trans, 2015, 44: 1406-1411

29 Kresse G, Furthmüller J. Efficient iterative schemes forab initio total-energy calculations using a plane-wave basis set. Phys Rev B, 1996, 54: 11169-11186

30 Blöchl PE. Projector augmented-wave method. Phys Rev B, 1994 , 50: 17953-17979

31 Perdew JP, Zunger A. Self-interaction correction to density-functional approximations for many-electron systems. Phys Rev B, 1981, 23: 5048-5079

32 Himmetoglu B, Floris A, De gironcoli S, et al. Hubbard-corrected DFT energy functionals: the LDA+U description of correlated systems. Int J Quantum Chem, 2014, 114: 14-49

33 Maeda K, Higashi M, Siritanaratkul B, et al. $\mathrm{SrNbO}_{2} \mathrm{~N}$ as a watersplitting photoanode with a wide visible-light absorption band. J Am Chem Soc, 2011, 133: 12334-12337

34 Yamada T, Sadakiyo M, Kitagawa H. High proton conductivity of one-dimensional ferrous oxalate dihydrate. J Am Chem Soc, 2009, 131: 3144-3145

35 Echigo T, Kimata M. Single-crystal X-ray diffraction and spectroscopic studies on humboldtine and lindbergite: weak Jahn-Teller effect of $\mathrm{Fe}^{2+}$ ion. Phys Chem Minerals, 2008, 35: 467-475

36 D'antonio MC, Wladimirsky A, Palacios D, et al. Spectroscopic investigations of iron(II) and iron(III) oxalates. J Braz Chem Soc, 2009, 20: 445-450

37 Angermann A, Töpfer J. Synthesis of magnetite nanoparticles by thermal decomposition of ferrous oxalate dihydrate. J Mater Sci, 2008, 43: 5123-5130

38 Fan $\mathrm{X}$, Zhang L, Cheng R, et al. Construction of graphitic $\mathrm{C}_{3} \mathrm{~N}_{4}$ based intramolecular donor-acceptor conjugated copolymers for photocatalytic hydrogen evolution. ACS Catal, 2015, 5: 5008-5015

39 Hafner J. Ab-initio simulations of materials using VASP: density-functional theory and beyond. J Comput Chem, 2008, 29: 2044-2078

40 Chu S, Wang Y, Guo Y, et al. Band structure engineering of carbon nitride: in search of a polymer photocatalyst with high photooxidation property. ACS Catal, 2013, 3: 912-919

41 Fan X, Xing Z, Shu Z, et al. Improved photocatalytic activity of g- $\mathrm{C}_{3} \mathrm{~N}_{4}$ derived from cyanamide-urea solution. RSC Adv, 2015, 5: 8323-8328

42 Dong G, Zhao K, Zhang L. Carbon self-doping induced high electronic conductivity and photoreactivity of $\mathrm{g}-\mathrm{C}_{3} \mathrm{~N}_{4}$. Chem Commun, 2012, 48: 6178-6180

43 Liu G, Niu P, Yin L, et al. a-Sulfur crystals as a visible-light-active photocatalyst. J Am Chem Soc, 2012, 134: 9070-9073

44 Fenton HJH. Oxidation of tartaric acid in presence of iron. J Chem Soc Trans, 1894, 65: 899-910

45 Neyens E, Baeyens J. A review of classic Fenton's peroxidation as an advanced oxidation technique. J Hazard Mater, 2003, 98: 33-50

46 Ruppert G, Bauer R, Heisler G. The photo-Fenton reaction - an effective photochemical wastewater treatment process. J Photochem Photobio A-Chem, 1993, 73: 75-78

Acknowledgments This work was supported by the National Key Basic Research Program of China (2013CB933200), the National High-tech R\&D Program of China (2012AA062703), Jiangsu National Synergetic Innovation Center for Advanced Materials (SICAM) and the Youth Innovation Promotion Association CAS (2012200).

Author contributions Fan X, Zhang L, and Shi J conceived the study. Fan X performed the experiments with help from Li M, Wang M, Zhou X, Cheng $\mathrm{R}$ and Zhou Y. Fan X wrote the paper with support from Zhang L and Shi J. All authors contributed to the general discussion.

Conflict of interest The authors declare that they have no conflict of interest.

Supplementary information Supplementary data are available in the online version of the paper. 


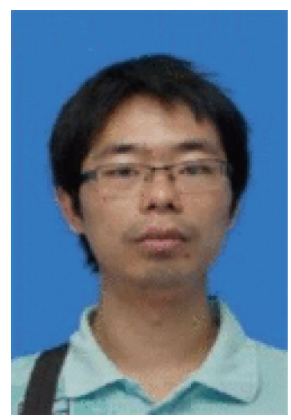

Xiangqian Fan obtained his BSc degree (2010) from South-Central University for Nationalities and MSc degree (2014) from Shanghai Institute of Ceramics, Chinese Academic of Sciences. He is now a research assistant in Shanghai Institute of Ceramics. His current research focuses on the development of novel photocatalysts for water splitting and pollutants degradation.

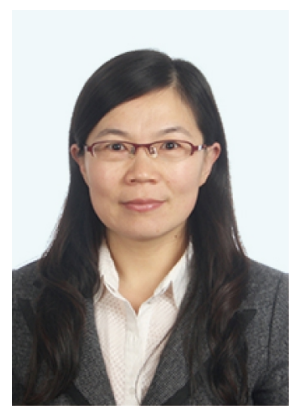

Lingxia Zhang received her PhD degree from Shanghai Institute of Ceramics, Chinese Academy of Sciences in 2003. She has been working at the institute after graduation. Currently her research mainly includes mesoporous and low-dimensional materials applied in artificial photosynthesis and environmental purification.

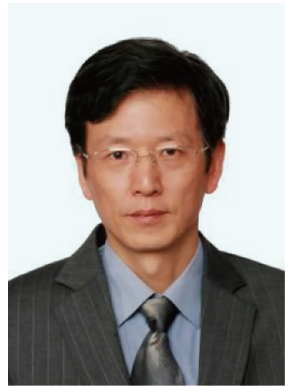

Jianlin Shi received his BSc degree from Nanjing University of Technology in 1983. He obtained his PhD degree in 1989 at Shanghai Institute of Ceramics, Chinese Academy of Sciences, and has been working at the institute since then. He worked on the processing science of advanced ceramics, solid state sintering theory of advanced ceramics, and high temperature reliability of structural ceramics from 1983 to 1998. Presently his main research interest includes the structural design and synthesis of mesoporous materials and mesostructured nanocomposites, and the catalytic and biomedical performances of the materials for applications in environmental protection and nanomedicine.

\section{二水合草酸亚铁: 一种兼具光催化氧化和光芬顿氧化能力的配位聚合物}

㚞向前, 张玲霞*, 李孟丽, 王敏, 周晓霞, 程若霖, 周亚君, 施剑林 ${ }^{*}$

摘要 最近, 配位聚合物作为一种引人注目的光催化剂已经引起了很多研究者的兴趣. 但是危险耗时的制备方法使它的应用受到了限制. 本文采用便捷的制备方法合成了一种简单的线性配位聚合物 “二水合草酸亚铁”, 并证实了其光催化降解染料的活性和能力. 同时, 我们 提出了一种独特的结合了传统光催化氧化和光Fenton氧化的双途径催化氧化机理. 二水合草酸亚铁优异的光催化性能及其经济简单的合 成方法, 使其有望成为一种有效的降解有机染料的光催化剂. 